\title{
O VALOR DA LIQUIDEZ: UM ESTUDO EXPLORATÓRIO NAS EMPRESAS BRASILEIRAS DO SETOR DE ENERGIA ELÉTRICA
}

\author{
Ercílio Zanolla* \\ erciliozanolla@hotmail.com \\ César Augusto Tibúrcio Silva** \\ cesaraugustotibursilva@gmail.com \\ *Universidade Federal de Goiás - GO / Brasil \\ **Universidade de Brasília - DF / Brasil
}

http://dx.doi.org/10.1590/1413-2311.041.57359

Recebido em 28/07/2015

Aprovado em 03/05/2017

Disponibilizado em 31/05/2017

Avaliado pelo sistema "double blind review"

Revista Eletrônica de Administração

Editora-chefe: Andrea Oltramari

ISSN 1413-2311 (versão "on line")

Editada pela Escola de Administração da Universidade Federal do Rio Grande do Sul

Periodicidade: Quadrimestral

Sistema requerido: Adobe Acrobat Reader

\section{RESUMO}

O estudo revisita a literatura da contabilidade e da economia para analisar a epistemologia da expressão conceito de 'liquidez' com o objetivo de explorar o seu valor ou custo para a empresa. A investigação caracteriza-se como um estudo exploratório por buscar fundamentar, entender e utilizar a liquidez como métrica de avaliação econômica, ou seja, criação de valor. Para tanto, o custo e o retorno da liquidez são necessários. Calcula-se o custo da liquidez por meio do modelo dinâmico do capital de giro, conforme Fleuriet et al (1978), e para o retorno da liquidez utiliza-se o retorno sobre o ciclo financeiro, conforme definido por Silva (1998). O ciclo financeiro compõe o cálculo do custo da liquidez por expressar o período de tempo que a empresa necessita, efetivamente, de financiamentos para manter determinado nível de liquidez, necessidade de capital de giro. O estudo empírico é realizado em uma amostra de 24 empresas brasileiras do setor de energia elétrica. Os dados secundários utilizados no cálculo das variáveis são referentes ao ano de 2011 e foram obtidos no banco de dados da economática. A análise foca a relação entre o valor da liquidez e as variáveis: ciclo financeiro, 
retorno sobre o ciclo financeiro, necessidade de capital de giro e margem de lucro bruta. Os resultados apontam que essas variáveis influenciam na determinação do valor da liquidez. Assim, para criar valor à empresa, o nível de liquidez definido pela gestão do capital de giro e evidenciado pela amplitude do ciclo financeiro, é de importância fundamental. Constata-se que o indicador valor da liquidez é uma ferramenta importante e eficiente tanto para a avaliação econômica como também para monitoramento de desempenho da gestão da empresa.

Palavras- Chave: liquidez; valor da liquidez; capital de giro.

\title{
VALUE OF LIQUIDITY: AN EXPLORATORY STUDY IN THE BRAZILIAN COMPANIES OF ELECTRICITY SECTOR
}

\begin{abstract}
The study revisits the literature of accounting and economics to analyze the concept and epistemology of expression 'liquidity' with the aims to explore its value or cost for the company. The research is characterized as an exploratory study to fundament, understand and to use the liquid as a metric of economic evaluation, value creation. Therefore, the cost and return of liquidity are needed. The cost of liquidity is calculated through the dynamic model of working capital, as Fleuriet et al (1978), and for the return of liquidity is used the return on the financial cycle, as defined by Silva (1998). The financial cycle enter in the calculation of cost of liquidity by expressing the time that the company needs, effectively, to finance and to maintain certain level of liquidity, need for working capital. The empirical study is conducted in a sample of 24 Brazilian companies of electricity sector. The secondary data used in the calculation of variables are of year 2011 and were obtained from of data base of economática. The analysis focus of relationship between the value of liquidity and the variables: financial cycle, return on financial cycle, need for working capital and gross profit margin. The results show that these variables influence in the determining of value of liquidity. So, to create value the company, the level of liquidity defined by management of working capital and evidenced by amplitude of financial cycle, is of fundamental importance. It appears that the indicator value of liquidity is an important and efficient tool for the economic evaluation with also for performance monitoring of company management.
\end{abstract}


Key-words: liquidity, value of liquidity, working capital.

\title{
VALOR DE LA LIQUIDEZ: UN ESTUDIO EXPLORATÓRIO EN LAS EMPRESAS BRASILEÑAS DEL SECTOR ELÉCTRICO
}

\begin{abstract}
RESUMEN
El estudio vuelve a la literatura de la contabilidad y la economía para analizar lo concepto e la epistemología de la expresión "liquidez" con el fin de explorar su valor o costo para la empresa. La investigación se caracteriza por ser un estudio exploratorio para buscar apoyo, comprender y utilizar la liquidez como una métrica de evaluación económica, es decir, la creación de valor. Por lo tanto, es necesario el costo y el retorno de la liquidez. Se calcula el coste de la liquidez por el modelo dinámico de capital de trabajo, como Fleuriet et al (1978), y el retorno de la liquidez se utiliza la rentabilidad del ciclo financiero, definido por Silva (1998). El ciclo financiero comprende el cálculo del coste de la liquidez mediante la expresión del tempo en que la empresa necesita para financiar e para mantener cierto nivel de liquidez, la necesidad de capital de trabajo. El estudio empírico se realiza sobre una muestra de 24 empresas brasileñas en el sector eléctrico. Los datos secundarios utilizados en el cálculo de las variables son del año 2011 y se obtuvieron de la base de datos de Economática. El análisis se centra en la relación entre el valor de las variables de liquidez: ciclo financiero, el rendimiento del ciclo financiero, la necesidad de capital de trabajo y el margen de beneficio bruto. Los resultados muestran que estas variables influyen en la determinación del valor de la liquidez. Por lo tanto, para crear valor para la empresa, el nivel de liquidez se define en la gestión de capital de trabajo y demuestra la amplitud del ciclo financiero, es de importancia fundamental. Parece que el valor del indicador de la liquidez es un instrumento importante y eficaz tanto para la evaluación económica, sino también para la supervisión del rendimiento de la gestión de la empresa.
\end{abstract}

Palabras- Clave: liquidez; valor de la liquidez; capital de trabajo.

\section{INTRODUÇÃO}


O estudo da liquidez requer persistência e parcimônia. Em finanças e no mercado, liquidez é um elemento importante para avaliar o desempenho da empresa e, consequentemente, a continuidade de suas operações. A parcimônia por que a expressão liquidez suscita divergências quanto ao seu entendimento e aplicação empírica.

O objetivo desse estudo é avaliar a liquidez a partir da análise epistemológica da expressão 'liquidez'. Revisita-se a teoria da liquidez em busca de subsídios para fundamentar e tentar sistematizar o valor ou o custo da liquidez para a empresa.

Na literatura, várias abordagens da liquidez são usadas. Na Teoria Geral do Emprego, do Juro e da Moeda, elaborada em 1936 por John Maynard Keynes (1985), denominada de Teoria Geral, propõe, na teoria da preferência pela liquidez, outra concepção de liquidez à visão tradicional e, destaca o papel da moeda enquanto ativo em processos de decisão e a função da taxa de juros como elemento monetário da dinâmica econômica de mercado na busca pelo equilíbrio entre investimentos, produção e poupança. Quando Keynes se volta às instituições financeiras trata da relação entre ativos e passivos, monetários, aproxima-se, desta forma, do conceito de liquidez encontrado na literatura contábil.

Com isso, busca-se contribuir com a literatura específica e com a determinação de criação de valor pelas empresas através de uma gestão eficiente da liquidez.

Primeiramente, o estudo trata da revisão bibliográfica de liquidez quanto aos aspectos epistemológicos como quanto à relação entre o nível de liquidez e seu custo e valor para a empresa. Em seguida, busca verificar empiricamente o objeto de estudo para, ao final, fazer as reflexões conclusivas e descrever as referências de pesquisa consultadas.

\section{LIQUIDEZ: EPISTEMOLOGIA E CONCEITOS}

A moeda, ativo considerado perfeitamente líquido, é usada e aceita sem restrições e riscos na execução de $\operatorname{contratos}^{1}$ dentro do grau de disponibilidade. Para Carvalho (1996, p. 47), “A pedra fundamental da análise monetária de Keynes (e pós-keynesianos) é a relação entre moeda e contratos." Carvalho cita Davidson (1978) para descrever que "a moeda tornase um ativo precisamente por causa de sua capacidade de liquidação de obrigações contratuais

\footnotetext{
${ }^{1}$ "Contratos futuros denominado em moeda são elementos essenciais da coordenação de uma economia onde a produção é organizada por agentes privados autônomos em busca de ganhos individuais." (CARVALHO, 1996, p. 47).
} 
nas datas aprazadas" e nos dizeres de Carvalho (1996, p. 47) "essa é a fonte de seu atributo de liquidez." Também, atribui que "outros ativos podem compartilhar essa propriedade, dependendo do seu grau de conversibilidade na moeda propriamente dita, isto é, do grau de risco envolvido na sua troca por moeda." (CARVALHO, 1996, p. 47).

O interesse e a demanda por moeda, na visão Keynesiana (1985), justifica-se em promover políticas de transação (recebimentos e pagamentos), precaução quanto ao cumprimento dos contratos e especulação com o intuito de obter vantagens financeiras.

A teoria da escola clássica do pensamento econômico, contestada por Keynes, defende a acumulação de moeda como forma de reservar valor (riqueza), em detrimento a riscos contratuais mensuráveis e alternativas de investimentos. Na concepção clássica, a poupança determinaria o investimento e a taxa de juros definiria qual decisão entre as opções. No entanto, o investimento em ativos reprodutíveis também se apresenta como alternativa à acumulação de valor.

Keynes (1985) define que os gastos são determinados pela produção e pelo emprego (renda), demanda efetiva ${ }^{2}$. Também, na teoria da preferência pela liquidez, a moeda passa a exercer um papel capaz de influenciar decisões de poupança e investimento, mediadas pela taxa de juros, e a quantidade de moeda seria influenciada pelo nível de renda dos agentes econômicos. Assim, em uma economia monetária o comportamento da moeda deve ser considerado na busca do equilíbrio (KEYNES, 1971/1983. V. 13, P. 409; apud Carvalho, 1996).

Em teoria geral a liquidez seria definida entre a decisão de investimento em moeda e outros ativos reprodutíveis e, essa decisão, seria influenciada pela taxa de juros (KEYNES, 1985). Assim, a determinação de taxa de juros para dois ou vários ativos direciona a preferência para a liquidez ou para o ganho conforme a opção pela transação, precaução ou a especulação.

Carvalho (1996, p. 47) cita Max Weber para descrever que numa economia capitalista os indivíduos envolvidos na produção, racionalmente buscam vantagens e cita Marx para definir "moeda como forma geral de riqueza" e "capaz de liquidar qualquer tipo de compromisso contratual". Destaca-se, dessa forma, que a moeda ou o grau de

\footnotetext{
${ }^{2}$ A demanda efetiva de Keynes (1936) se opõe ao conceito de que a oferta é capaz de gerar demanda.
} 
conversibilidade de ativos em moeda são determinantes da capacidade de pagamento da empresa e, consequentemente, da sua liquidez.

Para Carvalho (1996, p. 48) a moeda “[...] se constitui no meio mais adequado à implementação de estratégias defensivas em face do futuro incerto.” Ainda complementa que "é um ativo cujo retorno vem na forma de um prêmio de liquidez". Assim, pode-se ressaltar que a liquidez é condição pré-estabelecida para fazer frente á dificuldades financeiras futuras e a própria continuidade do empreendimento.

Quanto ao prêmio de liquidez, infere-se definir os ganhos econômicos decorrentes quanto às opções definidas na teoria da preferência pela liquidez, seja, a atenção na transação, na precaução ou na especulação, definida, logicamente, pela taxa de juros ou retorno gerado pelo investimento em moeda ou em outros ativos. O prêmio de liquidez é claramente definido quando Carvalho (1996, p. 48) descreve que "outros ativos não oferecem a mesma defesa contra a incerteza e compensam essa imperfeição pagando alguma classe de juros aos seus detentores." Ainda, Carvalho (1996, p. 49) complementa que "para que os detentores de riqueza aceitem reter formas menos flexíveis de riqueza, é preciso que seu risco seja compensado pecuniariamente pela reduzida riqueza de outros ativos que não a moeda." Amado (2004, p. 502) contribui com essa análise ao afirmar que "a liquidez de um ativo é definida como a propriedade de transformação do referido ativo em outra mercadoria instantaneamente". Destaca a velocidade de transformação e a manutenção de valor como componentes da mensuração da liquidez e, consequentemente, a influência da gestão da liquidez é percebida em seu valor.

Carvalho (1996, p. 49) complementa que "quanto maior a iliquidez de um ativo, maior tem de ser, em equilíbrio, a compensação paga para convencer os detentores de riqueza a aceitarem os riscos que ele representa."

Assim, o arcabouço teórico da teoria da liquidez fundamenta e confirma que tanto a opção pela liquidez como seu nível de acumulação representa um valor ou custo para a empresa.

Silva (1998, p. 91) corrobora afirmando que existe uma relação inversa entre o retorno e o ciclo financeiro da empresa. Entende-se por ciclo financeiro o nível de liquidez dos ativos. $\mathrm{O}$ autor complementa que quando o ciclo tende ao infinito o retorno tende a zero. 
Outros autores confirmam empiricamente a afirmação de Silva (1998) como Karaduman, Akbas, Caliskan e Durer (2011). Para García-Teruel e Martínez-Solano (2007); e Lazaridis e Tryfonidis (2006) a gestão de capital de giro e, consequentemente, a liquidez, afeta o valor da empresa.

Para melhor entender o prêmio de liquidez e o trad-off entre o custo de manter um determinado nível de liquidez e o retorno, Costa (1995, p. 9), descreve que "o dinheiro é o ativo plenamente líquido, não porque não rende juros (ou porque é escasso), mas sim pela ausência de custo de conversão para atuar em sua outra função, a função meio de pagamento.”

Ainda para Costa (1995, p. 6) "a velocidade de circulação, em seu aspecto mais importante, é fenômeno de risco". Assim, pode-se inferir que o nível de conversibilidade de ativos em moeda é medida de risco e essencial para se determinar a liquidez.

Costa (1995) usa o modelo de Hicks para responder que o financiamento de longo prazo deve ser usado para financiar investimentos em capital fixo. $\mathrm{O}$ autor argumenta que nesse caso não há efeito direto na liquidez, apenas na capacidade de endividamento devido ao risco crescente.

Assim, o nível de liquidez seria mantido e, então, de acordo com Silva (1998) também a relação com retorno seria mantida. Desta forma, a capacidade de pagamento e o desempenho da empresa seriam mantidos.

\section{LIQUIDEZ CONTÁBIL: ORIGEM E EVOLUÇÃO}

Na economia, a liquidez começou a ser definida com a Teoria Geral de Keynes na década de 1930. Na área contábil, em 1868 a Inglaterra passou a exigir legalmente a separação do balanço patrimonial em capital circulante e capital fixo, ou seja, uma classificação por ordem de liquidez recomendada e utilizada na elaboração e divulgação dos balanços atuais (NEPOMUCENO, 2008).

Para Myers (1974) o quociente entre o ativo circulante e o passivo circulante é indicador de liquidez mais antigo e popular, denominado de liquidez corrente (LC). Por outro lado, a diferença entre o ativo circulante e o passivo circulante também é utilizada para expressar a liquidez, denominada de capital circulante líquido (CCL).

Nos Estados Unidos o conceito de CCL começou a ser utilizado espontaneamente a 
partir da adoção do Accounting Principles Board (APB) $\mathrm{n}^{\circ} 3$, The Statement of Source and Application of Funds, na década de 1960. No entanto, foi regulamentado em março de 1971 com a edição do Accounting Principles Board (APB) $\mathrm{n}^{\circ} 19$, Statement of changes in financial position. No entanto, o conceito de CCL foi abandonado pelo conceito de caixa evidenciado pela Demonstração do Fluxo de Caixa que foi exigida primeiramente nos Estados Unidos, em 1987, por meio do SFAS no 95 o que incentivou o uso em outros países.

No Brasil, a variação do CCL era evidenciada pela demonstração das origens e aplicações de recursos (DOAR), primeiramente pelo Banco Central, em 1972, através da circular de $n^{\circ}$ 179. Mas, foi somente em 1976, com o advento da Lei $n^{\circ}$ 6.404, que se regulamentou a elaboração e divulgação da DOAR pelas empresas brasileiras. No entanto, com o advento da lei 11.638 de dezembro de 2007 o conceito de CCL foi substituído pelo conceito de caixa e equivalentes a caixa através da demonstração do fluxo de caixa (DFC), substituindo a DOAR.

A DFC classifica e evidencia o fluxo de caixa em atividades operacionais, atividades de investimento e atividades de financiamento. $\mathrm{O}$ fluxo de caixa das atividades operacionais (FCO) é uma métrica de desempenho que evidencia o caixa gerado no período através de atividades relacionadas com as operações da empresa e representa, efetivamente, o nível de liquidez da empresa.

No entanto, o FCO não substituiu as métricas de liquidez tradicionais tanto no meio acadêmico como no mercado. Métrica similar ao FCO bastante utilizada é o Earnings before interest, tax, depreciation and amortization (EBITDA) sendo, recentemente, sua divulgação regulamentada pela Instrução n. 527 de 04/10/2012 da Comissão de Valores Mobiliários. No entanto, representa somente a capacidade ou potencial da empresa gerar caixa.

Em 1978, Michel Fleuriet, Ricardo Kehdy e Georges Blanc em pesquisa realizada em pequenas e médias empresas brasileiras desenvolveram uma métrica de liquidez denominada de modelo dinâmico de capital de giro. O modelo calcula a necessidade de capital (NCG) pela diferença do valor do ativo circulante operacional e passivo circulante operacional. A NCG emprega a mesma metodologia de cálculo do CCL, no entanto, apenas com ativos e passivos circulantes operacionais.

\section{LIQUIDEZ: FINANCIAMENTO, CUSTO E RETORNO}




\subsection{Financiamento da Liquidez}

A liquidez contábil é determinada por valores reconhecidos nos balanços, ativos e passivos circulantes. O financiamento do investimento que determina a liquidez tem sua origem em fontes de recursos financeiros de terceiros e de capital próprio, considerando que parte dos ativos circulantes é financiada com recursos operacionais. Para Costa (1995, p. 16), investimentos em capital fixo deveriam ser financiados com recursos de longo prazo, assim, não haveria efeito direto na liquidez. Quanto ao capital de giro a parcela não financiada com recursos operacionais correntes (fornecedores) é financiada com recursos financeiros ou com capital próprio ou por ambos. Existe um custo de financiamento entre as alternativas possíveis: custo do capital de terceiros $(K i)$ também denominado custo da dívida, custo do capital próprio $(K e)$ ou o custo médio ponderado de capital (CMPC). O custo da dívida, $K i$, é determinado pelo quociente entre as despesas financeiras, líquidas da economia do imposto de renda, e o passivo oneroso. A remuneração do capital mantido pelos sócios ou acionistas está prevista na legislação societária brasileira com base na taxa de juros de longo prazo, TJLP. No entanto, por ser um a taxa de captação do Tesouro Nacional, não tem relação com o risco da empresa e com o custo de oportunidade (ASSAF NETO, 2010, p. 235). Uma alternativa para o cálculo do custo do capital próprio é o Capital Asset Princing Model (CAPM). O CAPM prevê uma relação linear entre a expectativa do valor de um ativo e o risco sistêmico da empresa em relação ao mercado e estabelece que a taxa de retorno esperada das ações aumenta em relação à covariância do risco dos fluxos de caixa (NEGAKIS. 2005).

O financiamento do investimento da liquidez pode advir, conforme o caso, de fontes de recursos tanto de terceiros como de capital próprio, cujo custo é definido por $K i$ e $K e$, respectivamente. Assim, utiliza-se o CMPC por contemplar a participação de cada fonte na estrutura de financiamento.

\subsection{Custo da Liquidez}

Para determinar o custo da liquidez é preciso conhecer a taxa do custo financeiro, descrita no tópico anterior, e o montante do valor dos ativos que definem a liquidez a ser financiado por um determinado período.

Considerando apenas os principais elementos do ciclo operacional da empresa o montante da liquidez é determinado pela seguinte equação:

$$
N C G=C+E-F
$$


Sendo $\mathrm{C}=$ Clientes $; \mathrm{E}=$ estoques $; \mathrm{F}=$ Fornecedores.

O custo da liquidez (cliq) é referente ao custo de manter esse investimento, $N C G$, por um determinado período de tempo, ciclo financeiro. Assim, primeiramente calcula-se a taxa do custo do ciclo financeiro para, posteriormente, calcular o montante do custo da liquidez, conforme as equações 2 e 3 a seguir:

$$
\begin{aligned}
& c c f=\frac{T x}{360} \times c f \\
& c l i q=c c f \times N C G
\end{aligned}
$$

Onde $T x=$ taxa do custo financeiro $; C G=$ necessidade de capital de giro $c f=$ ciclo financeiro; $c c f=$ custo do ciclo financeiro.

Para calcular o custo do ciclo financeiro, conforme equação dois, utilizou-se a taxa de juros simples. A justificativa é por se tratar de um estudo experimental que visa desenvolver um modelo para calcular o custo da liquidez. Assim, nesse caso específico, a taxa de juros efetiva não é relevante.

A $T x$ pode ser determinada pelo custo da dívida, custo do capital próprio ou o custo médio de capital conforme as fontes de financiamento utilizadas para financiar o montante de liquidez, $N C G$.

\subsection{Retorno da Liquidez}

Para calcular o retorno da liquidez é necessário conhecer o montante da liquidez, equação um, e uma taxa de retorno. Quanto a taxa de retorno é possível usar como proxy o conceito de retorno sobre o ciclo financeiro, conforme Silva (1998), que é dado por:

$$
r=\frac{m}{c f \times(1-m)}
$$

Onde:

$r=$ retorno sobre o ciclo financeiro

$m=$ margem de lucro (preço de venda /custo dos produtos vendidos)

$c f=$ ciclo financeiro 
O $c f$ é o período em que os investimentos em clientes e estoques (capital de giro) são financiados com recursos financeiros ou próprios. Segundo Silva (1998, p. 90) o retorno sobre o ciclo financeiro incorpora "a lucratividade e a liquidez, que são os dois mais importantes objetivos da administração do capital de giro".

A partir do cálculo da taxa de retorno sobre o $c f$, equação (3), pode-se calcular o retorno sobre o montante de investimento que define o nível de liquidez, NCG, equação (1). Assim, têm-se o retorno da liquidez (rliq):

$$
r l i q=r \times N C G
$$

equação (5)

Desta forma, o valor da liquidez (vliq) é representado pela diferença entre o retorno e o custo da liquidez, equação um e equação dois, respectivamente, ou seja, vliq $=$ rliq - cliq .

\section{METODOLOGIA DE PESQUISA}

Para esta investigação, propõe-se um estudo exploratório por buscar no referencial teórico subsídios para fundamentar e entender os impactos da opção pela utilização da liquidez na criação de valor para a empresa (GRESSLER, 2004). A metodologia para análise do referencial teórico será subsidiada pela pesquisa bibliográfica.

Quanto aos procedimentos metodológicos, seguem a coleta dos dados secundários das empresas brasileiras do setor de energia elétrica referentes ao ano de 2011 com o uso do banco de dados 'Economática'. Para anular o efeito tamanho os dados foram divididos pelo ativo total. Após, as variáveis da equação um e três são calculadas para, posteriormente calcular, através das equações dois e quatro, o custo e o retorno da liquidez, respectivamente, e, pela diferença, o valor da liquidez.

A amostra é composta de 24 empresas de um total de 50. Portanto, foram excluídas 26 por apresentarem informações incompletas (ou empresas com $c f$ negativo) ou por não terem realizado operações no capital de giro durante o ano de 2011.

A taxa de juros para calcular o custo da liquidez, equação dois, também foi obtida do banco de dados Economática e utilizou-se como proxy o custo da dívida, $K i$, por considerar que a maior parte dos investimento em capital de giro, NCG, é financiada com recursos onerosos de terceiros. 
A análise do resultado abordará o spread entre o custo e o retorno da liquidez, valor da liquidez, em relação ao ciclo financeiro, ao retorno sobre o ciclo financeiro, à necessidade de capital de giro e à margem de lucro bruta. A partir da identificação do grupo de empresas que cria valor através da liquidez e o grupo que não cria, procura-se identificar e analisar as principais causas através das políticas de investimento e financiamento, ou seja, da gestão do nível de liquidez utilizado pelas empresas. A correlação entre as variáveis está evidencia por gráficos editados pelo software gretl.

\section{ANÁLISE DOS RESULTADOS}

Analisando o gráfico 1 percebe-se que existe uma relação negativa entre o valor da liquidez e o período de tempo que a empresa precisa para financiar a necessidade de capital de giro, com recursos onerosos, ciclo financeiro. Assim, quanto menor o ciclo financeiro existe a tendência do valor da liquidez ser maior. Esta afirmação é confirmada pelo índice de correlação entre o valor da liquidez e o ciclo financeiro de $-0,7856$.

Destaca-se a importância da gestão do capital de giro, especificamente dos principais elementos, clientes, estoques e fornecedores na criação de valor para empresa e, consequentemente, a contribuição efetiva do ciclo financeiro.

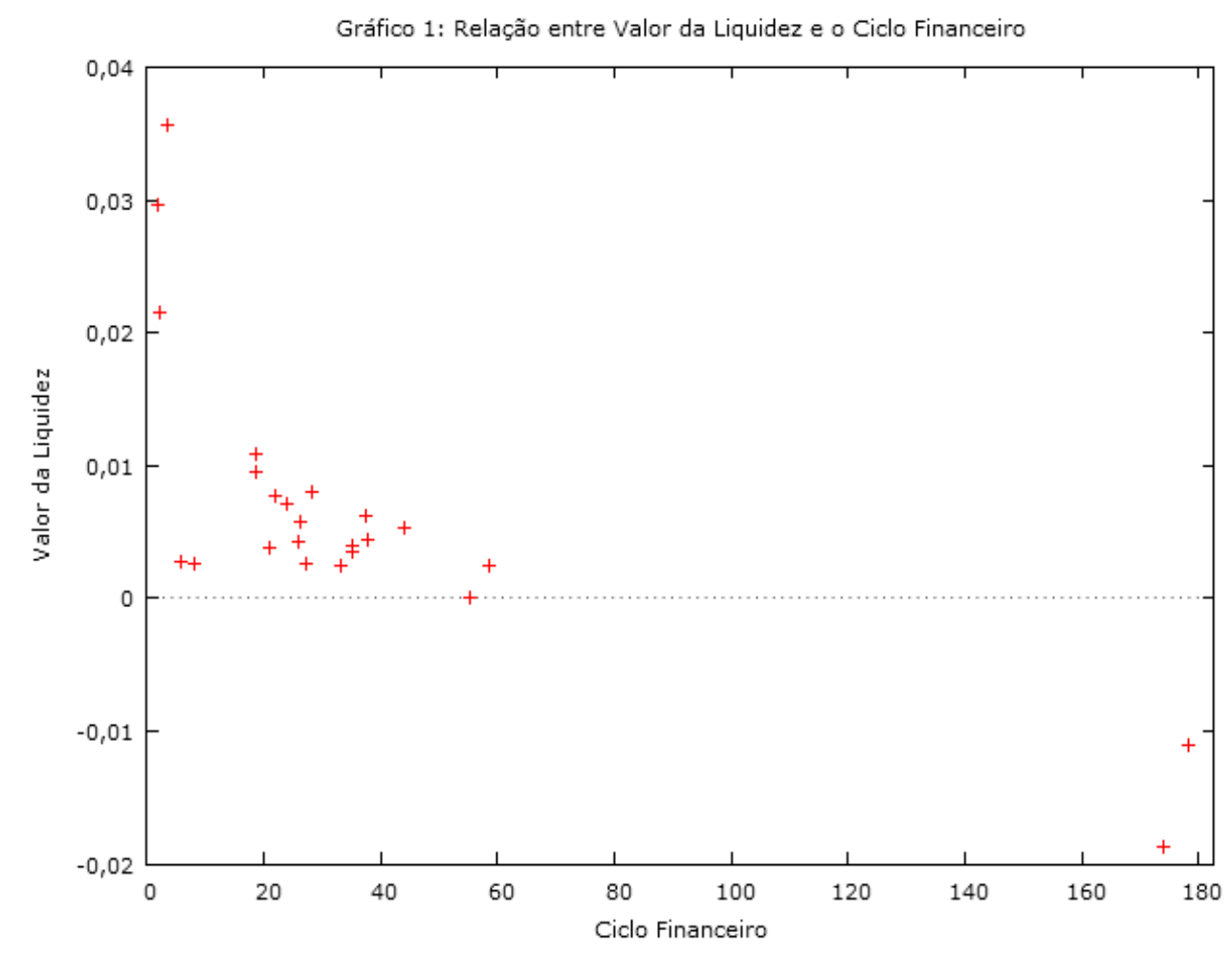


Fonte: os autores

Quanto ao retorno sobre o ciclo financeiro, gráfico 2, percebe-se uma relação positiva com o valor da liquidez. O índice de correlação entre as variáveis de 0,8168 confirma que quanto maior o retorno sobre o ciclo financeiro maior tende a ser o valor da liquidez. $\mathrm{O}$ retorno sobre o ciclo financeiro é influenciado pela margem de lucro bruta, definida pelo preço de venda e custo dos produtos comercializados e pela amplitude do próprio ciclo. Assim, ciclo menor e maior margem asseguram um maior retorno e, consequentemente, incrementam valor à empresa. Esta análise permite segregar, detalhar e monitorar as variáveis que efetivamente contribuem para uma gestão eficiente, ou seja, que cria valor para a empresa.

Também, observa-se no gráfico 2 que das empresas pesquisadas três se destacam por apresentar valor da liquidez superior. Isto é explicado pelas elevadas taxas de retorno sobre o ciclo financeiro (ver tabela em anexo).

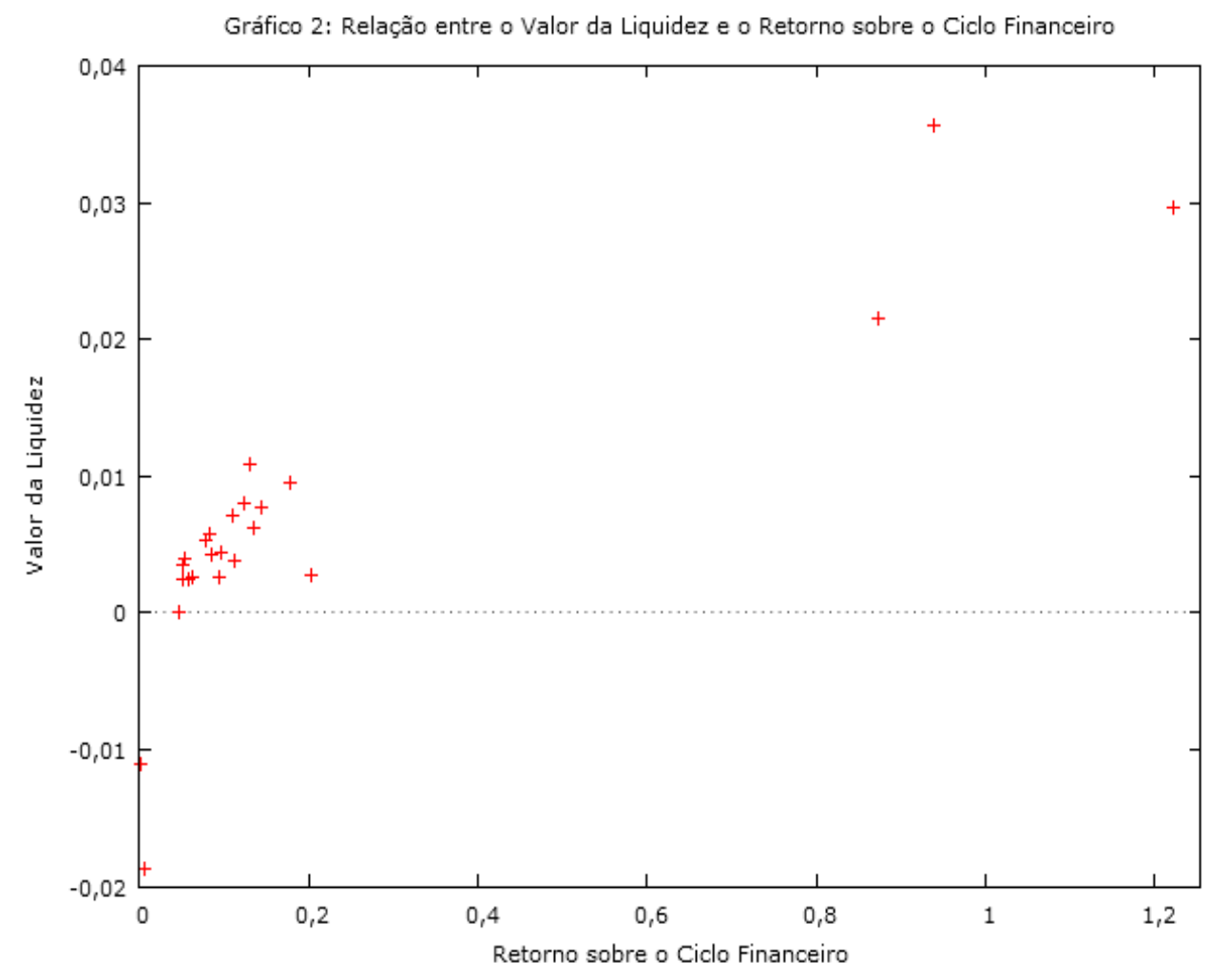

Fonte: os autores

Estas empresas apresentam uma margem de lucro bruta compatível com as demais empresas, no entanto, possuem um ciclo financeiro pequeno o que resulta num retorno maior. Evidenciam, desta forma, adequada e eficiente gestão do capital de giro. 
O gráfico 3 evidencia uma relação negativa entre o valor da liquidez e o montante de liquidez, NCG. A correlação apurada entre essas variáveis é de -0,72253287. Assim, a priori, o excesso de liquidez pode influenciar negativamente a criação de valor.

A análise gráfica das quatro empresas que apresentam maior necessidade de capital de giro, acima de 0,10, aponta que as duas empresas que tem valor da liquidez maior que zero possuem ciclo financeiro e margem de lucro bruta compatível com as demais. As duas empresas que destruíram valor da liquidez apresentam baixa margem de lucro e elevado ciclo financeiro (ver tabela em anexo).

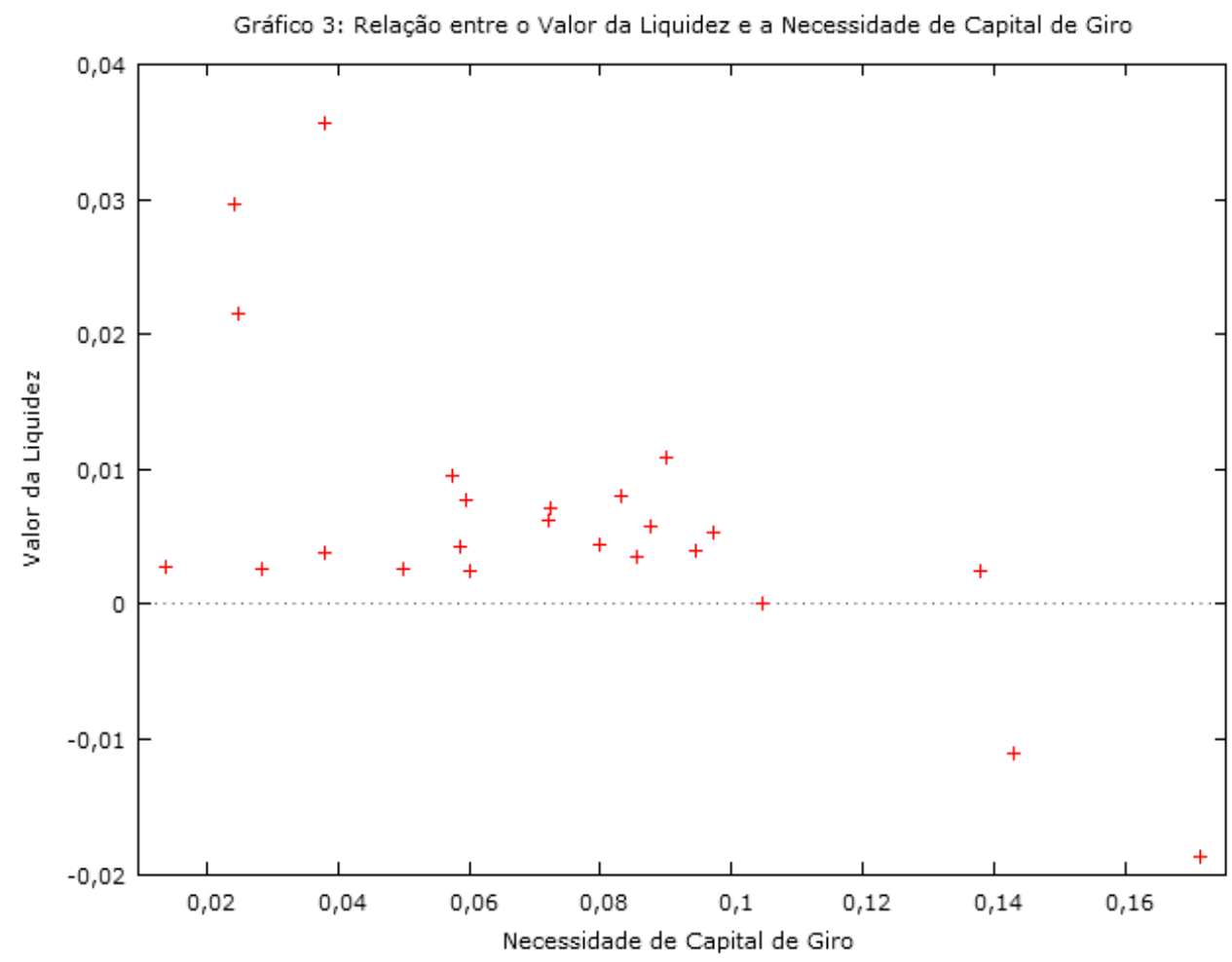

Fonte: os autores

O gráfico 4 evidencia que a margem de lucro bruta é uma das causas da destruição de valor para a empresa. 


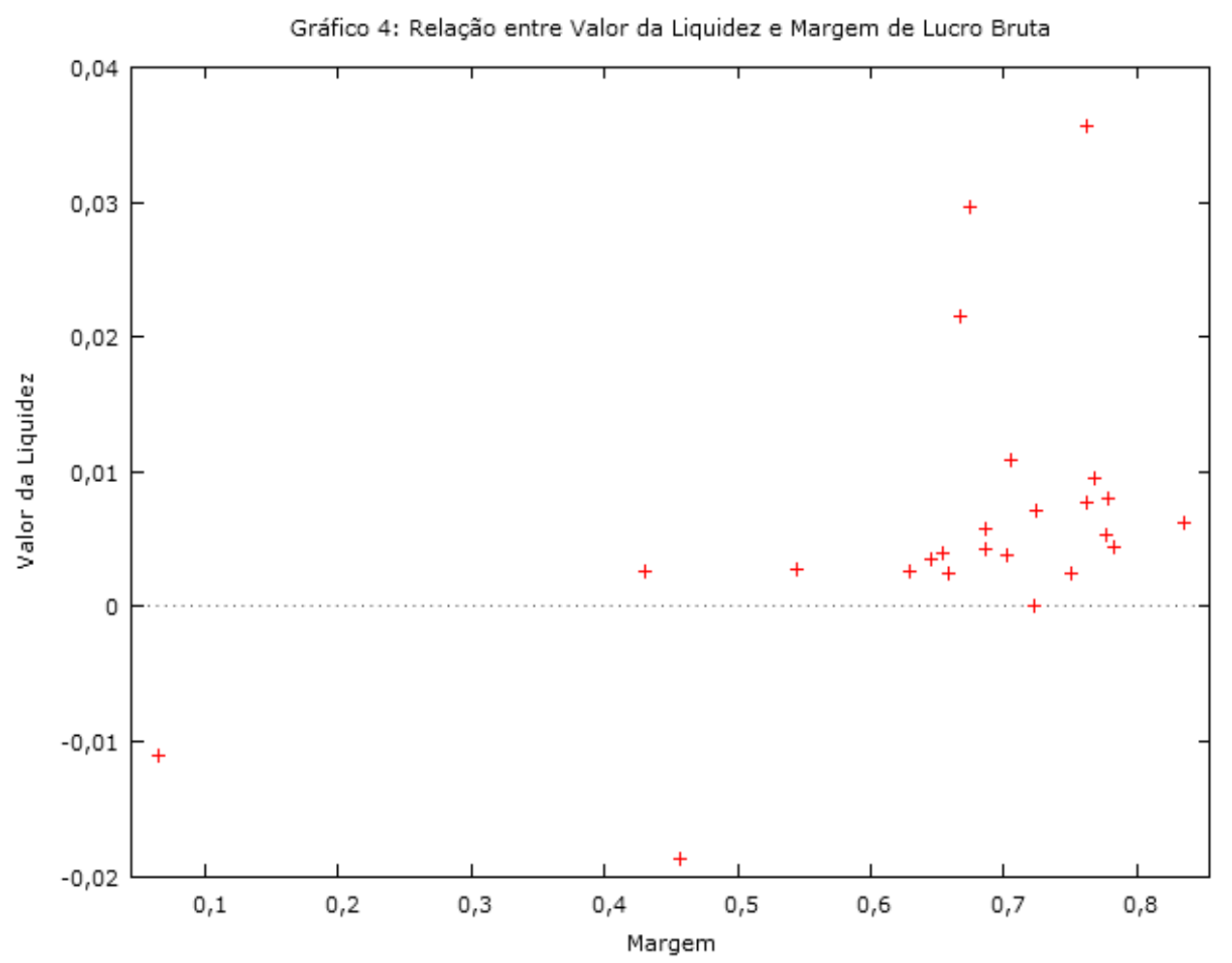

Fonte: os autores

Das três empresas com margem menor que 0,5 duas destruíram valor. A empresa que conseguiu criar valor da liquidez foi pelo baixo ciclo financeiro, aproximadamente 22 vezes menor das que destruíram valor (ver tabela $1 \mathrm{em}$ anexo). Constata-se, assim, que a conciliação entre o ciclo financeiro e a margem de lucro bruta é importante na criação de valor da liquidez. Essa análise gráfica é retratada também pelo expressivo índice de correlação de 0,5422 .

\section{CONCLUSÕES}

A pesquisa postulou fundamentar teoricamente e sistematizar o cálculo do valor da liquidez para as empresas, especificamente, do setor de energia elétrica brasileiro.

Primeiramente, a partir da literatura existente buscou-se, através da elaboração de equações, calcular o retorno e o custo da liquidez para determinar e mensurar o valor da liquidez. 
Foi estabelecida como proxy do montante de liquidez o valor da necessidade de capital de giro definida pelos principais elementos do capital de giro, clientes, estoques e fornecedores.

A taxa do custo financeiro dos recursos obtidos de terceiros foi utilizada para o cálculo do custo da liquidez. Por outro lado, foi utilizado o retorno sobre o ciclo financeiro, equação três, para se calcular o retorno da liquidez. Pela diferença entre o retorno e o custo, o valor da liquidez foi definido para as vinte e quatro empresas da amostra.

A análise do resultado se pautou na relação entre o valor da liquidez e as seguintes variáveis utilizadas na modelagem do estudo: ciclo financeiro, retorno sobre o ciclo financeiro, necessidade de capital de giro e margem de lucro bruta. Os achados apontam que a gestão dessas variáveis, de forma isolada ou agregada, influencia na determinação do valor da liquidez, criando ou destruindo valor. Assim, os objetivos da pesquisa foram alcançados ao mostrar e comprovar empiricamente a relevância da gestão do capital de giro, expressada na amplitude do ciclo financeiro, para criar valor da liquidez às empresas. Ainda, os achados, possibilitam vislumbrar que o valor da liquidez é um índice útil para analisar tanto o desempenho da empresa, criação de valor, como o desempenho do gestor. As variáveis que compõem o índice podem ser monitoradas e manipuladas em prol das metas de desempenho estabelecidas. Pode-se concluir que o índice valor da liquidez é uma ferramenta importante e eficiente para a avaliação de desempenho.

Sugere-se a continuação do estudo utilizando outros instrumentos como a análise de regressão e fazer testes numa amostra de empresas maior e de outros setores de atividade.

\section{ANEXO}

Tabela: 1: Empresas da amostra e variáveis analisadas

\begin{tabular}{|l|r|r|r|r|r|}
\hline Empresa & \multicolumn{1}{|c|}{ Cf } & NCG/AT & \multicolumn{1}{c|}{$\mathrm{m}$} & vliq. (\%/AT) \\
\hline Ampla Energ & 18,70 & 0,057 & 0,768 & 0,177 & 0,009 \\
\hline Ceb & 44,10 & 0,097 & 0,777 & 0,079 & 0,005 \\
\hline Ceee-Gt & 5,90 & 0,014 & 0,545 & 0,203 & 0,003 \\
\hline Celesc & 28,20 & 0,083 & 0,779 & 0,125 & 0,008 \\
\hline Celpa & 37,30 & 0,072 & 0,835 & 0,136 & 0,006 \\
\hline Celpe & 58,70 & 0,138 & 0,750 & 0,051 & 0,002 \\
\hline Cemar & 35,30 & 0,095 & 0,654 & 0,054 & 0,004 \\
\hline
\end{tabular}




\begin{tabular}{|l|r|r|r|r|r|}
\hline Cemat & 55,10 & 0,105 & 0,722 & 0,047 & 0,000 \\
\hline Cemig & 27,20 & 0,050 & 0,630 & 0,062 & 0,003 \\
\hline Coelba & 26,30 & 0,088 & 0,687 & 0,083 & 0,006 \\
\hline Coelce & 24,00 & 0,072 & 0,724 & 0,109 & 0,007 \\
\hline Copel & 20,90 & 0,038 & 0,702 & 0,113 & 0,004 \\
\hline CPFL Energia & 2,30 & 0,025 & 0,667 & 0,872 & 0,022 \\
\hline Elektro & 18,50 & 0,090 & 0,706 & 0,130 & 0,011 \\
\hline Eletropaulo & 3,40 & 0,038 & 0,762 & 0,940 & 0,036 \\
\hline Energias BR & 1,70 & 0,024 & 0,675 & 1,223 & 0,030 \\
\hline Energisa & 25,90 & 0,058 & 0,686 & 0,084 & 0,004 \\
\hline Equatorial & 35,00 & 0,086 & 0,645 & 0,052 & 0,003 \\
\hline Light S/A & 22,10 & 0,060 & 0,762 & 0,145 & 0,008 \\
\hline Neoenergia & 33,20 & 0,060 & 0,659 & 0,058 & 0,003 \\
\hline Rede Energia & 37,80 & 0,080 & 0,783 & 0,096 & 0,004 \\
\hline Taesa & 178,10 & 0,143 & 0,064 & 0,000 & $-0,011$ \\
\hline Tractebel & 8,10 & 0,028 & 0,430 & 0,093 & 0,003 \\
\hline Tran Paulist & 174,00 & 0,171 & 0,456 & 0,005 & $-0,019$ \\
\hline
\end{tabular}

Fonte: Os autores.

Obs.: Variáveis utilizadas para determinar o custo e retorno da liquidez, calculadas com dados, ponderados pelo ativo total, obtidos de uma amostra de 24 empresas brasileiras de energia elétrica do banco de dados Economática.

\section{REFERÊNCIAS}

AMADO, A. M. Preferência pela liquidez: o novo contexto financeiro internacional inviabiliza a teoria? Revista de Economia Política, São Paulo, v. 24, n. 4 (96), p. 500-513, out./dez. 2004.

APB - Accounting Principles Board $n^{\circ} 3$. The Statement of Source and Application of Funds. New York: APB, Out. 1963.

APB - Accounting Principles Board $n^{\circ}$ 19. Statement of changes in financial position. New York: APB, Mar. 1971.

ASSAF NETO, A. Estrutura e análise de balanços: um enfoque econômico-financeiro. 9. ed. São Paulo: Atlas, 2010. 
BANCO CENTRAL DO BRASIL. Lei circular 179 de 11 de maio de 1972. Disponível em:<http://www.bcb.gov.br/busca.asp?consulta=lei circular 179/1972>. Acesso em: 26 nov. 2012.

BRASIL. Lei 6.404 de 15 de dezembro de 1976. Disponível em:

<http://www.planalto.gov.br/ccivil_03/Leis/L6404consol.htm>. Acesso em: 26 nov 2012.

CARVALHO, F. J. Cardim de. Sobre a centralidade da teoria da preferência pela liquidez na macroeconomia pós-keynesiana. Ensaios FEE, Porto Alegre, v. 17, p. 42-77, 1996.

COMISSÃO VALORES MOBILIARIOS (CVM). Instrução CVM n. 527. Rio de Janeiro, RJ: CVM, 2012.

COSTA, F. N. Hicks e a liquidez. Ensaios FEE, Porto Alegre, v. 16, n. 2, p. 703-726, 1995.

FLEURIET, M.; KEHDY, R.; BLANC, G. A dinâmica financeira das empresas

brasileiras. Belo Horizonte: Fundação Dom Cabra, 1978.

GARCIA-TERUEL, P. J.; MARTÍNEZ-SOLANO, P. Effects of working capital management on SME profitability. International Journal of Managerial Finance, Bingley, v. 3, n. 2, p. 164-177, 2007.

GRESSLER, L. A. Introdução à pesquisa: projetos e relatórios. 2. ed. São Paulo: Edições Loyola, 2004.

KARADUMAN, H. A. et al. The relationship between working capital management and profitability: evidence from an emerging market. International Research Journal of Finance and Economics, Victoria, n. 62, p. 61-67, 2011.

KEYNES, J. M. A teoria geral do emprego, do juro e da moeda: Inflação e deflação. 2. ed. São Paulo: Nova Cultural, 1985.

LAZARIDIS, I.; TRYFONIDIS, D. Relationship between working capital management and profitability of listed companies in the Athens stock exchange. Journal of Financial Management and Analysis, [s.1.], v. 19, n. 1, p. 26-35. 2006.

MYERS, J. N. Análise das demonstrações financeiras. São Paulo: Atlas, 1974. 
NEGAKIS, C. J. Accounting and Capital Markets Research: A Review. Managerial Finance, Bingley, v. 31, n. 2, 2005.

NEPOMUCENO, V. Teoria da contabilidade. Curitiba: Juruá, 2008.

SILVA, C. A. T. Contribuição ao estudo do capital de giro a partir do retorno sobre o ciclo financeiro. Contabilidade Gestão e Finanças - UnB Contábil, Brasília, v. 1, n. 2, 1998. 